\title{
Social Constructs in Predicting Corruptive Attitudes and Behavior from the Theory of Planned Behavior Perspective
}

Submitted 11/07/19, $1^{\text {st }}$ revision 13/08/19, $2^{\text {nd }}$ revision 20/09/19, accepted 26/10/19

\author{
Zulaikha $^{1}$, Paulus T. Basuki Hadiprajitno ${ }^{2}$, Muhammad Ihlasul Amal ${ }^{3}$
}

\begin{abstract}
:
Purpose: This research examines the attitude and behavior of corruption/fraud using the social construct, the theory of fraud triangle, Theory of Planned Behavior, and social psychology.

Design/methodology/approach: The quantitative approach in this study was carried out by collecting survey data using a questionnaire instrument directly applied to 400 respondents in some cities in Indonesia. The analysis is conducted with SPSS, Wrap-PLS and Structural Equation Models (SEM).

Findings: The results show that the attitude and corrupt behavior of the community can be influenced by the existence of social values in the form of community habits and community mindset that is reflected in the social construct variables.

Practical implications: The study underlines the importance of corruption eradication, especially in public services and public education to avoid corrupt behavior.

Originality/value: The examination was done by paying more attention to the possible effect of social construction on attitudes, subjective norms, and control of individual or group behavior, which in turn affect the intention to commit corruption.
\end{abstract}

Keywords: Theory of planned behavior, social construct, opportunity, pressure, corruption.

JEL code: G34.

Paper type: Research article.

\footnotetext{
${ }^{1}$ Faculty of Economics and Business, Diponegoro University, Semarang, Indonesia, email: zulaikha2505@gmail.com

${ }^{2}$ Faculty of Economics and Business, Diponegoro University, Semarang, Indonesia

${ }^{3}$ Faculty of Economics and Business, Universitas Negeri Semarang, Semarang, Indonesia, email: ihlashul@outlook.com
} 


\section{Introduction}

According to Prabowo (2014), Indonesia has a Corruption Perception Index (CPI) ranked 118 out of 174 most corrupt countries by Transparency International (2012). In an effort to eradicate corruption in Indonesia, the Corruption Eradication Commission reported that in 2016, the GPA rose to rank 90 out of 176 countries (Corruption Eradication Commission, 2017). However, corruption in Indonesia still occurs systematically and extends so that it not only harms state finances, but also violates the social and economic rights of the community at large (Nurhayati and Gumbira, 2017; Suhariyanto, 2018).

Referring to the fraud triangle (Cressey, 1973) there are several factors that influence it, namely pressure, opportunites, rationalization. By adopting Dorminey et al. (2012) stating that there are psychological and social aspects that can be antecedent variables rationalisas, this study explores social construct variables as antiseden rationalization which is proxied by perceived attitude variables, norms, and behavioral control (Cohen et al., 2010). Furthermore, these three variables were tested for their influence on corrupt intentions and behavior. This research examines the attitude and behavior corruption/fraud using the social construct by using the theory of fraud triangle, Theory of Planned Behavior, and social psychology. This is done by paying more attention to the possible effect of social construction on attitudes, subjective norms, and control of individual or group behavior, which in turn affect the intention to commit corruption.

\section{Literature Review and Hypotheses}

\subsection{Effect of Attitudes on Intention to Corrupt}

Every individual has an attitude, character, or set of values that allows them to have a corrupt intention and generates the intention to engage in dishonest actions that lead to a corrupt behavior. Attitudes toward corrupt behavior can affect someone having the intention to do corruption. Telgen (2006) reveals the characteristics of the procurement of goods and services in the public sector, namely the demand for exemplary attitudes for government officials related to the procurement of goods for example, not only in terms of ethical standards but also in terms of efficiency and effectiveness of their operations. The attitude that tolerates corrupt actions will encourage individuals to have the intention to commit corruption. Cohen et al. (2010) state that corrupt attitudes are attitudes that support actions that lead to acts of corruption. In other words, if someone has an attitude that supports corrupt actions, it is predicted that the person concerned will have the intention to commit corrupt actions or behavior.

H1: Attitudes influence the intention to commit corruption. 


\subsection{Subjective Norm Effect on Intention to Corrupt}

Subjective norms are components of the theory of Planned Behavior (TPB) which describe subjective opinions or norms held by individuals (Cohen et al., 2010). Thai (2001) stated that the environment is one of the factors that influences the ability of a system to achieve its intended purpose. Subjective norms can contain positive or negative values. Subjective norms are measured by indicators that tend to be negative, so the direction of relations with fraudulent intentions becomes positive.

This describes the individual's perception wather it is easy or not to do something (Cohen et al., 2010). If someone perceives it easy to commit fraud and is in an environment that supports fraud, then the person concerned will have the intention to commit fraud, which in turn will commit fraud. This factor can be called the selfefficacy beliefs from fraud perpetrators who become intentions to commit fraud. These norms affect individuals to commit fraud (Beck and Ajzen, 1991). If individuals have intense subjective norms that support a corrupt behavior, people tend to rationalize the corrupt actions. This is predicted to grow the intention to commit corruption. If all members have the same perception it will led to an environment that rationalizes the corrupt actions.

\section{H2: Subjective norms influence the intention to do corruption}

\subsection{Effect of Perceived Behavioral Control on Intention to do Corruption}

Perceived behavioral control is defined as the individual perception of weather it will be easy or not to do something (Cohen et al., 2010). If someone perceives it easy to do corruption, the person concerned will have the intention to commit corruption, which in turn will form a corrupt behavior. This factor can be called the self-efficacy beliefs of the perpetrators of corruption which is the intention to do corruption. Kravtsova et al. (2017) state that people who internalize materialistic values will tend to accustom to corruption. This can also be interpreted that the behavioral control can affect the intention and justify the corrupt behavior. Zulaikha and Basuki (2016) provide empirical evidence that perceived behavioral control is indicated by the presence of greed and attitude towards controlling more fraud perpetrators, and this variable can encourage individuals or groups to intend to commit fraud on the procurement of government goods and services.

\section{H3: Perceived behavior control influences corrupt intentions.}

\subsection{Effect of Corruptive Intentions on Corrupt Behavior}

The theory of planned behavior (Ajzen, 1991) states that there are three factors that influence someones intention to behave corruptly, namely: corrupt attitudes, subjective norms, and Perceived behavioral control to do corruption. This intention to do corruption is accompanied by opportunities and financial as well as other 
pressures that can lead to corrupt actions (Cohen et al., 2010). Each individual has an attitude, character, or set of values that allows them to have the intention to engage in corruption and to consciously and intentionally commit dishonest actions that lead to corrupt behavior (Beck and Ajzen, 1991). This study examines whether intentions are followed by pressure and opportunities or not. Potential corruption actors will process the profit and the loss if they commit corruption, so that if the benefits they get are greater, corruption will occur.

H4: The intention to engage in corruption has an effect on the corrupt behavior.

\subsection{Effects of Financial Pressure on Corrupt Behavior}

Pressure, according to Cressey (1973) and Fisher (2015) is a non-shareable, both perceived and real financial burden. This such pressure, in some cases of corruption in Indonesia, can arise due to greed, the desire to have excessive material wealth, among government officials/ people representatives (Prabowo, 2014). Cressey (1973) states that financial pressure is a component of a fraud triangle that can trigger corrupt actions. An inadequate income can lead to financial pressure. Lambsdorff (1999) found that that income factors are one of the factors that influence the occurrence of corruption, including corruption carried out through irregularities in government procurement of goods/services.

Furthermore, Fisher (2015) states that some forms of real financial pressure include burdensome debt, hospital bills, and so on. The perceived financial pressures can result from an inadequate income compared to the results of their work, or the high risk of being involved in legal problems often becomes a justification for committing fraud (Cressey, 1973). The imbalance between the income received by the government apparatus compared to the family needs at a reasonable level will force them to creatively seek additional income to meet their daily needs (BPKP, 1999). Rezaee (2005) also states that inadequate incentives can contribute to a corrupt behavior in the presentation of financial reporting. Here, an income that triggers financial pressure can have a direct effect on the corrupt behavior, and could even encourage it.

\section{H5: Financial pressure has a positive effect on corrupt behavior.}

\subsection{Effect of Opportunities against Corrupt Behavior}

Opportunities for corrupt actions are often associated with weaknesses in the control system and the inability of fraud to be detected (Dorminey, 2012). Fisher (2012) cites the statement of Cressey (1973) which states that there are two aspects of opportunities that can trigger fraud. The first is the existence of information that makes fraudsters able to commit fraud. Second is the technical ability of the perpetrators. Equipped with the acquisition of information and technical capabilities of the perpetrators, the weaknesses of the procedure will be used by individuals to 
commit corruption or fraud. Thai (2001) states that the system and procedures used for the procurement of goods/services have an effect on the success of a system in achieving its intended goals. If there is an effective system and procedure, it will be able to minimize the opportunity to implement corrupt actions. Conversely, if the system and the procedures are weak, the corrupt actions will be encouraged. In addition to the lack of transparency, the less effective supervisory function also becomes an opportunity that can lead to corruption (Sartono, 2006).

H6: Opportunities (weaknesses in the state/regional financial systems and procedures) affect corrupt behavior.

\section{Theoretical Framework}

This research is a model of causality research, namely it consists of one dependent variable (corrupt behavior) which is influenced by 5 independent variables and one intervening variable (intention to engage in corruption). While the independent variables are: 1) attitude 2) subjective norms and 3). perceived behavioral control. 4) financial pressure, 5) opportunities due to system weaknesses.

Figure 1. Research Model

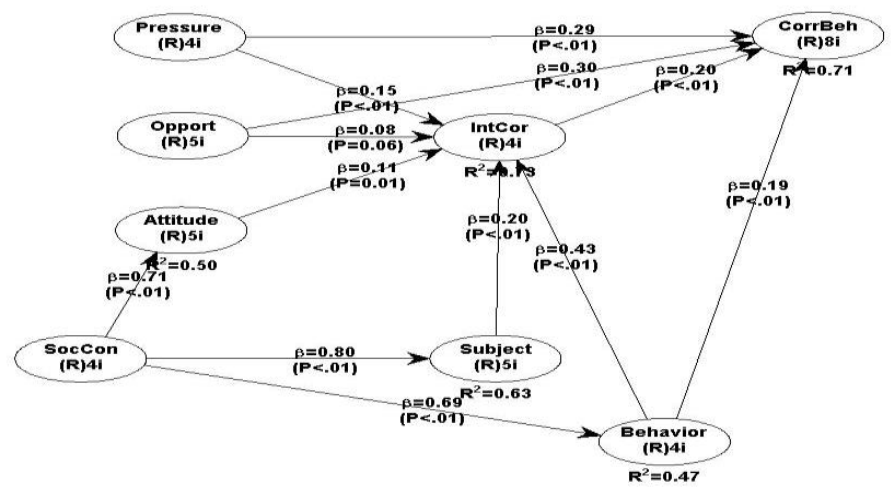

\section{Methodology}

The quantitative approach in this study was carried out by collecting survey data using a questionnaire instrument directly to respondents. The research sites to be selected are cities where the national risk-based planning arrangements are held at Government Agencies in Semarang, Public Accountability Supervision in Purbalingga, and work meetings of the Association of Sulawesi Young Entrepreneurs in Manado, and in several other regions in East and Central Java. From the total number of 400 distributed questionnaires, 330 copies have been 
collected back, out of which 9 have been incompletedly filled in so that the final data to be analyzed was 321 .

Variable of attitude is a reflection of statement or judgment relating to an object, event, or society that has elements of cognition and affective that are corrupt, measured by 3 attitude components, namely cognitive, affective, and behavioral aspects which are reflected in 5 indicators. Subjective norms are an overview of respondents' perceptions of subjective opinions that individuals have about corrupt actions, measured by 4 indicators. Perceived behavioral control describes the perceptions of respondents about the perpetrators of corruption and beliefs about their potential that shows greed, moral hazard, and easy collusion to act corruptively, measured by 4 items about respondents' assessment of how far corruptors have the potential to commit corrupt actions. The intention to corrupt in this research is cognitive and affective, because of the existence of the environment and the personal point of view. Variable of intention to corrupt is the cognitive and affective aspect of corrupt actors that will trigger corrupt actions, measured by 4 questions.

All variables are measured by a five-point Likert scale from 1 (strongly disagree) to 5 (strongly agree). The research data obtained will be analyzed by quantitative approach with SPSS, Wrap-PLS, and specifically, hypothesis testing is used in the analysis of the Structural Equation Model (SEM) with the acceptance provisions of the Hypothesis at the level of $\alpha=5 \%$.

\section{Results}

\subsection{Reliability Test}

The Reliability Test in Table 1 presents the results of the reliability testing of all research data, containing 321 observations, and the result shows that the value of all Cronbach's alpha based on Standardized Items have a value over 67.1\%. Therefore it can be concluded that the measurement instrument or variable indicator is declared reliable, so that it can be forwarded to the data analysis stage to test the proposed hypothesis.

Table 1. Data Reliability Test Results

\begin{tabular}{|l|l|l|}
\hline Variables & Cronbach's alpha & Verification \\
\hline Corrupt behavior & 0.847 & Reliable \\
\hline Opportunity & 0.759 & Reliable \\
\hline Pressure & 0.796 & Reliable \\
\hline Attitude & 0.865 & Reliable \\
\hline Subjective norms (Sub. norms) & 0.825 & Reliable \\
\hline Perceived Behavioral Control (Behav. Control) & 0.882 & Reliable \\
\hline Intent to corrupt & 0.833 & Reliable \\
\hline Social construct & 0.861 & Reliable \\
\hline
\end{tabular}




\subsection{Descriptive Statistics of Social Construct}

This variable is explored from the habits and mindset of the community that is predicted to influence the attitudes of the people who tend to be permissive to corrupt behavior, subjective norms, and perceived behavioral control that determines the rationalization of intention to be corrupt. This variable is measured by 5 indicators, the result of the descriptive analysis is presented in Table 2.

Table 2. Descriptive Statistics of social construction

\begin{tabular}{|l|l|l|l|l|l|}
\hline & $\mathrm{N}$ & Minimum & Maximum & Mean & Std. Deviation \\
\hline SocCon & 321 & 5.0 & 25.0 & 18.819 & 3.5967 \\
\hline SC1 & 321 & 1.0 & 5.0 & 3.857 & 0.8899 \\
\hline SC2 & 321 & 1.0 & 5.0 & 3.648 & 0.9240 \\
\hline SC3 & 321 & 1.0 & 5.0 & 3.854 & 0.8294 \\
\hline SC4 & 321 & 1.0 & 5.0 & 3.664 & 0.9214 \\
\hline SC5 & 321 & 1.0 & 5.0 & 3.798 & 0.9183 \\
\hline Valid N (listwise) & 321 & & & & \\
\hline
\end{tabular}

The first indicator of the value of social construct (SC1) is: It becomes a habit for the community to give something as an expression of gratitude. The second indicator of the value of social construct (SC2) is: Feeling uncomfortable if one has already delivered a service or finished a project and does not get a reward, "something", as an expression of gratitude. This indicator has an average value of 3.648 with a standard deviation of $=0.9240$. The third indicator of the value of social construct (SC3) is: The community feels proud and judges the success by owned/showed material/wealth, without questioning where it is obtained from. The average value of this indicator is 3.854 with a standard deviation of 0.8294 .

The fourth indicator of the value of social construct (SC4) is: The habit of aprreciating, admiring and consider clever, figures which can always get out of trouble with great personal benefits. Respondents' answers showed an average value of 3.664 and a standard deviation value of 0.9214 . The fifth indicator (SC5) is: The frequency of the public expressing "how much do you dare to pay? or "we pay piro"? is an expression to show how bold it is when someone gets extra services or facilities, or gets a profit. This indicator has an average value of 3.798 with a standard deviation of 0.9183 .

\subsection{Model Fit and Quality Indices Test Results}

From the results of the analysis as in Table 3, it can be stated that the model is fit to be used to test the proposed hypothesis, because it meets the fit criteria for the path analysis test. Thus the model can be continued to be tested with the Warp-PLS Program. 
Table 3. Model fit and Quality Indices test results

\begin{tabular}{|l|l|l|l|}
\hline Indices & Results & Indices & Results \\
\hline $\begin{array}{l}\text { Average path coefficient } \\
\text { (APC) }\end{array}$ & $0.345, \mathrm{p}<0.001$ & $\begin{array}{l}\text { Tenenhaus GoF } \\
(\mathrm{GoF})\end{array}$ & $\begin{array}{l}0.619, \text { small }>=0.1, \\
\text { medium }>=0.25, \\
\text { large }>=0.36\end{array}$ \\
\hline $\begin{array}{l}\text { Average } \\
\text { (ARS) }\end{array}$ & $0.610, \mathrm{p}<0.001$ & $\begin{array}{l}\text { Sympson's paradox } \\
\text { ratio (SPR) }\end{array}$ & $\begin{array}{l}1.000, \text { acceptable if } \\
>=0.7, \text { ideally =1 }\end{array}$ \\
\hline $\begin{array}{l}\text { Average adjusted R- } \\
\text { squared (AARS) }\end{array}$ & $0.607, \mathrm{p}<0.001$ & $\begin{array}{l}\text { R-squared } \\
\text { contribution ratio } \\
\text { (RSCR) }\end{array}$ & $\begin{array}{l}1.000, \text { acceptable if } \\
>=0.9, \text { ideally =1 }\end{array}$ \\
\hline $\begin{array}{l}\text { Average block VIF } \\
\text { AVIF) }\end{array}$ & $\begin{array}{l}2.693, \\
\text { acceptable if }<= \\
5, \text { ideally }<=3.3\end{array}$ & $\begin{array}{l}\text { Statistical } \\
\text { sppression ratio } \\
\text { (SSR) }\end{array}$ & $\begin{array}{l}1.000, \text { acceptable if } \\
>=0.7\end{array}$ \\
\hline $\begin{array}{l}\text { Average full collinearity } \\
\text { VIF (AFVIF) }\end{array}$ & $\begin{array}{l}\text { Nonlinear bivariate } \\
\text { acceptable if }<= \\
\text { causality direction } \\
\text { ratio (NLBCDR) }\end{array}$ & $\begin{array}{l}1.000, \text { acceptable if } \\
>=0.7\end{array}$ \\
\hline
\end{tabular}

\subsection{Hypothesis Testing}

The results of the study revealed that the attitude variable had a significant positive effect on IntCor/intent to Corrupt with $\beta=0.11 ; \mathrm{p}=0.01$; thus $\mathrm{H} 1$ is empirically supported so that the first hypothesis is accepted. Second, the Subject/Subjective norms variable has a significant positive effect on IntCorr with the $\beta$ coefficient $=$ $0.11 ; \mathrm{p}=0.01$. These results indicate that $\mathrm{H} 2$ is also empirically supported, so $\mathrm{H} 2$ is accepted. Third, the behavior/perceived behavior control has a positive effect on IntCorr/corrupt intention with the $\beta$ coefficient value $=0.43 ; \mathrm{p}=0.01$. This result also shows that the behavior control variable that is perceived has a significant positive effect on IntCor/intent to corrupt, so that $\mathrm{H} 3$ is also accepted.

This first model includes - pressurre and opportunity - as control variables which are also predicted to influence the intention to commit corruption. Pressure has a significant effect on the IntCorr/Intent to corrupt variable, while opportunity does not have a significant effect on IntCorr at level $\mathrm{p}<0.05$. It also shows that the presence of pressure can trigger intention to commit fraud. The results of this first model analysis can be interpreted that the first hypothesis $(\mathrm{H} 1)$, second $(\mathrm{H} 2)$, and third (H3) are empirically supported with $\mathrm{p}<0.05$. The analysis results show that the coefficient of determination $\mathrm{R} 2$ is 0.78 , indicating that the variability of the independent variable in influencing the dependent one is $78 \%$.

The results of the analysis show that the IntCor/intent to corrupt variable has a significant positive effect on corruption with the value of the $\beta$ coefficient $=0.20$ and $\mathrm{p}=0.01$; thus $\mathrm{H} 4$ is accepted. Fifth, the pressure variable has a significant effect on correlation with the $\beta$ coefficient value $=0.29 ; \mathrm{p}=0.01$. Thus, H5 is also accepted. Sixth, the opportunity has a positive effect on Corrbeh/Corrupt behavior with the $\beta$ coefficient $=0.30 ; p=0.01$. Thus, H6 is accepted. 
Table 4. Results of SEM Analysis

\begin{tabular}{|l|l|l|l|l|l|}
\hline Relationship Model & Hypothesis & $\beta$ & $\mathrm{p}$ & $\mathrm{R}^{2}$ & $\mathrm{p}>5 \%$ \\
\hline Attitude $\rightarrow$ IntCor & $\mathrm{H} 1$ & 0.11 & 0.01 & 0.78 & Accepted \\
\hline Subject $\rightarrow$ IntCor & $\mathrm{H} 2$ & 0.2 & $<0.01$ & 0.78 & Accepted \\
\hline Behavior $\rightarrow$ IntCor & $\mathrm{H} 3$ & 0.43 & $<0.01$ & 0.78 & Accepted \\
\hline IntCor $\rightarrow$ CorrBeh & $\mathrm{H} 4$ & 0.20 & $<0.01$ & 0.71 & Accepted \\
\hline Pressure $\rightarrow$ CorrBeh & H5 & 0.29 & $<0.01$ & 0.71 & Accepted \\
\hline Opport $\rightarrow$ CorrBeh & H6 & 0.30 & $<0.01$ & 0.71 & Accepted \\
\hline Behavior $\rightarrow$ CorrBeh & & 0.19 & $<0.01$ & 0.71 & Significant \\
\hline Pressure $\rightarrow$ intCor & & 0.15 & $<0.01$ & 0.78 & Significant \\
\hline Opport $\rightarrow$ IntCor & & 0.08 & 0.06 & 0.78 & Insignificant \\
\hline SocCon $\rightarrow$ Attitude & & 0.71 & $<0.01$ & 0.50 & Significant \\
\hline SocCon $\rightarrow$ Subject & & 0.80 & $<0.01$ & 0.63 & Significant \\
\hline SocCon $\rightarrow$ Behavior & & 0.69 & $<0.01$ & 0.47 & Significant \\
\hline
\end{tabular}

The test results from the second model show a determination coefficient $(\mathrm{R} 2)=0.71$. This second model includes the variable perceived behavioral as a control variable, and the result shows a significant positive effect of the control variable. From the results of this analysis it can be interpreted that the fourth hypothesis ( $\mathrm{H} 4)$, along with fifth (H5), and sixth (H6) hypotheses are accepted because it is empirically supported with a value of $\mathrm{p}<0.05$. The determination coefficient of this model is $71 \%$. This result also shows that the variability of the influence of the independent variable on the dependent variable in this model is $71 \%$ and the rest is influenced by other variables.

The results of the analysis show the influence of SocCon/Social construct variables on attitude, subjective norms (subject) and perceived behavioral control/perceived behavioral control (behavior). The results of the analysis show that the influence of SocCon/Social construct on attitude shows the value of the $\beta$ coefficient $=0.71 ; \mathrm{p}=$ $0.01, \mathrm{R} 2=0.50$. The influence of SocCon/Social construct on subject/subjective norms shows the value of the $\beta$ coefficient $=0.80 ; p=0.01, R 2=0.63$; and its effect on Behavior/Perceived behavioral control shows the value of the $\beta$ coefficient $=$ $0.69 ; \mathrm{p}=0.01, \mathrm{R} 2=0.47$. The results of the analysis concluded that the SocCon variable (socially constructed values) had a significant positive effect on attitude, subjective norms and on perceived behavioral control variables.

\subsection{Concluding Remarks}

The social construct variables in this study were explored and tested whether they influence the attitude, subject (subjective norms) and behavior variables (perceived behavioral control). The results show that social constructs have a positive effect on attitude variables, subjective norms, and perceived behavioral control with a significance level smaller than 0.05. The findings also show that the influence of social construct (SocCon) on attitude shows the coefficient $(\beta)=0.71$ and significance value $(p)=0.01$ with a value of $\mathrm{R} 2=0.50$. Furthermore, the influence 
of social construct on subjective norms (subject), shows the coefficient $(\beta)=0.80$ and significance value $(\mathrm{p})=0.01$ with the value of $\mathrm{R} 2=0.63$; and the influence of social construct on perceived behavioral control norms/subjective behavioral control (behavior), showing the coefficient $(\beta)=0.69$, the significance value $(p)=0.01$ with the value $\mathrm{R} 2=0.47$.

This study findings that are permissive attitudes toward corrupt behavior have a significant effect on corrupt intentions (supporting the first hypothesis), subjective norms have a significant effect on corrupt intentions (supporting the second hypothesis), perceived behavioral control on intention to do corruption, intention to do corruption or the existence of a permissive mindset of corrupt behavior has a significant effect on corrupt behavior. The financial pressure is directly proportional to the corrupt behavior, and the opportunity to influence a corrupt behavior is empirically supported. Attitudes, subjective norms, and behavioral control perceived by individuals who tend to be permissive to corrupt behavior are influenced by the value of social constructs, namely habits and thought patterns that can lead to corrupt behavior.

\section{References:}

Cohen, J., Ding, Y., Lesage, C. and Stolowy, H. 2012. Corporate fraud and managers' behavior: Evidence from the press. In Entrepreneurship, governance and ethics, 271-315, Springer, Dordrecht.

Corruption Eradication Commission. 2017. Annual Report 2016, https://www.kpk.go.id/id.

Donald, C.R. 1973. Other People's Money: A Study in the Social Psychology of Embezzlement. Patterson Smith \& Montclair.

Dorminey, J., Fleming, A.S., Kranacher, M.J. and Riley Jr, R.A. 2012. The evolution of fraud theory. Issues in accounting education, 27(2), 555-579.

Fisher, K. 2015. The Psychology of Fraud: What Motivates Fraudsters to Commit Crime? Available at SSRN 2596825.

Kravtsova, M., Oshchepkov, A. and Welzel, C. 2017. Values and corruption. Journal of Cross-Cultural Psychology, 48(2), 225-242.

Lambsdorff, J.G. 1999. Corruption in empirical research: A review. Transparency International.

Nurhayati, R. and Gumbira, S.W. 2017. Public accountability and corruption. Journal of Law and Justice, 6(1), 41-66.

Prabowo, H.Y. 2014. To be corrupt or not to be corrupt: Understanding the behavioral side of corruption in Indonesia. Journal of Money Laundering Control, 17(3), 306-326.

Rezaee, Z. 2005. Causes, consequences, and deterence of financial statement fraud. Critical Perspectives on Accounting, 16(3), 277-298.

Sartono. 2006. Analysis of Factors Affecting Irregularities in the Procurement of Goods / Services in the Environment of Government Agencies. Unpublished Thesis, Faculty of Economics, University of Indonesia.

Suhariyanto, B. 2018. Urgency of jurisprudency development of corporation punishment of corruption actors for effectiveness of law in Indonesia. Journal of Law and Justice, 7(3), 459-482. 
Telgen, J. 2006. Public Procurement in Perspective. In: International Public Procurement; Cases and Commentary, edited by Knight, L.A., Harland, C.M., Telgen, J., Callender, G., Thai, K.V. and McKen, K.E. Routledge.

Zulaikha, Z. and Hadiprajitno, P.T.B. 2016. Factors Affecting Procurement Fraud: a Study of the External Auditor's Perspective. Indonesian Financial Accounting Journal, 13(2), 194-220.

Ajzen, I. 1991. The theory of planned behavior. Organizational behavior and human decision processes, 50(2), 179-211.

BPKP/Financial and Development Supervisory Agency. 1999. National Corruption Eradication Strategy (SPKN). Jakarta: Financial and Development Supervisory Agency.

Thai, K.V. 2001. Public procurement re-examined. Journal of public procurement, 1(1), 9-50. 